\title{
Aquagenic Palmar Wrinkling Induced by Combined Use of Salazopyrin and Indomethacin
}

\author{
Özgür Gündüz ${ }^{a} \quad$ Kıvılcım Çınkır Özsaraça ${ }^{a}$ Mustafa Emre Ercin ${ }^{b}$ \\ Departments of ${ }^{a}$ Dermatology and ${ }^{b}$ Pathology, University of Kırıkkale, Kırıkkale, Turkey
}

\section{Key Words}

Aquaporin · Aquagenic palmar wrinkling · Cyclooxygenase - Indomethacin · Prostaglandins . Salazopyrin

\begin{abstract}
Aquagenic palmar wrinkling (APW) is an uncommon dermatological condition, which manifests as asymptomatic or tender palmar papules and may cause discomfort and manual functional limitations during its flares. Despite some studies implying a relationship between cystic fibrosis (CF) and APW, there are also reports of APW cases without an accompanying CF. In this report we describe a 19-year-old ankylosing spondylitis patient, who developed APW lesions after the start of combined salazopyrin and indomethacin treatment. His palmar lesions were resistant to topical corticosteroid and aluminium hydroxide therapy and disappeared only after stopping the anti-inflammatory drugs. With this report, we aim to highlight and address this underrecognized dermatological condition and possible role of aquaporins in its pathogenesis.
\end{abstract}

\section{Introduction}

Aquagenic palmar wrinkling (APW), also known as aquagenic palmar acrokeratoderma, is a rare skin condition triggered by contact with water. Brief contact in water induces translucent, white papules and plaques on the contact surfaces. Etiology of APW is unknown, but there are studies indicating an association with cystic fibrosis (CF) [1, 2] and some case reports implying various drugs as possible triggering factors [3-5]. Although called palmar wrinkling, similar lesions can be observed on other cutaneous surfaces after water exposure [6]. We describe an ankylosing spondylitis patient who manifested APW lesions four weeks after the start of salazopyrin and indomethacin combination therapy.

Özgür Gündüz

Kırıkkale Üniversitesi, Tıp Fakültesi

Dermatoloji AD, Millet Cad.

TR-71100 Kirikkale (Turkey)

E-Mail gunduzozgur@windowslive.com 


\section{Case Report}

A 19-year-old male with a 1-year history of ankylosing spondylitis, was referred to our clinic due to relapsing translucent-white papules and plaques on his palms which had started about 2 weeks ago. He was diagnosed with HLA-B27-positive ankylosing spondylitis according to ESSG and Amor criteria and had a history of irregular sulfasalazine use for the last 4 months due to severe joint pains and sacroiliitis. Two months before, indomethacin was added to his therapy regimen. At the time of admission, he was on sulfasalazine 2,000 $\mathrm{mg}$ /day plus indomethacin $75 \mathrm{mg} /$ day combination therapy for about 2 months. Dermatological examination revealed few minor aphthae on gingival mucosa, nevoid hypertrichosis on the left infrascapular area and a Becker nevus on the right abdominal lower quadrant. At the start of the physical examination, there weren't any cutaneous lesions on the patient's palms (fig. 1a). Following a 3-min hand wash under the tap water, white, flat papules appeared on both of his palms (fig. 1b, c). These palmar lesions persisted about $30 \mathrm{~min}$ before disappearing. A punch biopsy was performed in this active state. Histological evaluation showed compact orthohyperkeratosis and relative dilatation of eccrine ducts in the upper dermis (fig. 2a, b). Hyperplasia of the eccrine glandular epithelia was observed in the reticular dermis, and lumina of the eccrine glands had irregular shapes (fig. 2c).

Further evaluation for the oral aphthae revealed no underlying disease, such as Behçet's or inflammatory bowel disease and the patient declined further genetic testing for CF. Topical therapy with aluminium hydroxychloride 19\% cream was started, but it did not ameliorate the symptoms. At the end of the third week of therapy, topical mometasone furoate ointment $0.1 \%$ was prescribed. One month after the start of the combination therapy, APW still persisted. Only 4 weeks after the cessation of both anti-inflammatory drugs, symptoms of APW resolved and did not remit.

\section{Discussion}

We presume that the addition of indomethacin to the patient's therapy regimen is the triggering factor for the palmar lesions, since these lesions occurred after the start of indomethacin and resolved following its discontinuation. Also, the patient did not have any other medical or family history or physical examination findings consistent with $\mathrm{CF}$, which probably is the most reported disease to be in association with APW.

APW is a rare disease of unknown etiology and characterized by the transient occurrence of edematous white papules and plaques on the palms following contact with the water. There are about 30 reported cases of APW in literature and there are no controlled studies due to the rarity of the disease. Changes in the osmotic gradient across the membranes of eccrine gland epithelia and the following water influx into the eccrine ducts has been proposed [7] as the underlying factor to explain the pathogenesis of APW. Such an osmotic gradient exists across the eccrine duct epithelia of CF patients due to elevated salt concentrations in their sweat. This hypertonic sweat $\mathrm{CF}$ is the result of the mutation of the cystic fibrosis transmembrane regulator (CFTR) gene. This gene encodes CFTR protein, which acts as a chloride channel in the membrane of the epithelial cells. CFTR dysfunction results in decreased electrolyte reabsorption in the eccrine ducts and hypertonic sweat. Osmotic gradient due to hypertonic content of sweat of CF patients may play a role in APW [8]. Several reported cases [7-9] and studies [1, 2] support a possible association between APW and CF, but APW is not observed in all of the CF patients [1] and there are also case reports of APW in patients without $\mathrm{CF}[3,10]$. 
Considering the rapid change on palmar surfaces after water exposure and APW cases without $\mathrm{CF}$, dysfunction of another molecule participating in the rapid transport of water can be regarded as a plausible hypothesis. Aquaporins (AQP) are a family of proteins which are responsible for rapid water transport across the cell membrane and are expressed on mammalian skin [11]. It is shown that AQP5 is directly involved in sweat secretion and AQP3 is found in human keratinocytes [11]. Ma et al. [12] demonstrated decreased sweat secretion and AQP5 expression by sweat glands of mice, proposing a role for AQP in hypohydrosis. Kabashima et al. [13] reported aberrant expression of aquaporin 5 in the palmar sweat glands of a patient with APW and suggested that aquaporins may play a role in APW. Two recent studies show the effects of COX inhibitors on aquaporins. Jensen et al. [14] showed that prostaglandin (PG) inhibition by a COX inhibitor (ibuprofen) resulted in downregulation of urinary aquaporin 2 (u-AQP2) in the kidney epithelia of bilateral ureteral obstructed rats. Lauridsen et al. [15] have demonstrated that inhibition of prostaglandin synthesis by ibuprofen also leads to decreased levels of u-AQP2 indicating a decrease in the water transport via aquaporins. Case reports describing NSAID-related APW [2-4] and the aforementioned studies [14, 15] suggest a possible relation between dysregulation of epithelial AQPs due to COX inhibition and APW. The drugs used to treat our patient, indomethacin, salazopyrin (both of its subgroups, 5-aminosalicylate and sulfapyridine), are established COX inhibitors. The concurrent use of these potent COX inhibitors may be the trigger factor for our patient's condition. As stated by Lauridsen et al. [15], disturbance of epidermal PG synthesis by these drugs may lead to downregulation of epidermal aquaporins, which in turn may lead to water retention in keratinocytes. Although limited to several cases, evaluation of APW and epidermal AQP expression patterns and AQP gene mutations in COX inhibitor users, may provide valuable information about the pathogenesis of APW and also about the physiology of eccrine glands.

\section{References}

1 Garçon-Michel N, Roguedas-Contios AM, Rault G, Le Bihan J, Ramel S, Revert K, Dirou A, Misery L: Frequency of aquagenic palmoplantar keratoderma in cystic fibrosis: a new sign of cystic fibrosis? Br J Dermatol 2010;163:162-166.

-2 Tolland JP, Boyle J, Hall V, McKenna KE, et al: Aquagenic wrinkling of the palms in an adult cystic fibrosis population. Dermatology 2010;221:326-330.

-3 Khuu PT, Duncan KO, Kwan A, Hoyme HE, Bruckner AL: Unilateral aquagenic wrinkling of the palms associated with aspirin intake. Arch Dermatol 2006;142:1661-1662.

-4 Carder KR, Weston WL: Rofecoxib-induced instant aquagenic wrinkling of the palms. Pediatr Dermatol 2002;19:353-355.

5 Vildósola S, Ugalde A: Celecoxib-induced aquagenic keratoderma. Actas Dermosifiliogr 2005;96:537-539.

6 Flann S, Pembroke A: A localized form of aquagenic syringeal acrokeratoderma. Clin Exp Dermatol 2010;35:e147-e148.

7 Katz KA, Yan AC, Turner ML: Aquagenic wrinkling of the palms in patients with cystic fibrosis homozygous for the delta 508 CFTR mutation. Arch Dermatol 2005;141:621-624.

-8 Seitz CS, Gaigl Z, Bröcker EB, Trautmann A: Painful wrinkles in the bathtub: association with hyperhydrosis and cystic fibrosis. Dermatology 2008;216:22-26.

-9 Stewart LC, Doe SJ, Bourke SJ: Aquagenic palmar wrinkling as a presenting feature of cystic fibrosis gene dysfunction. Clin Exp Dermatol 2009;34:e647-e649.

10 Luo DQ, Li Y, Huang YB, Wu LC, He DY: Aquagenic syringeal acrokeratoderma in an adult man: case report and review of the literature. Clin Exp Dermatol 2009;34:e907-e909.

-11 Boury-Jamot M, Daraspe J, Bonté F, Perrier E, Schnebert S, Dumas M, Verbavatz JM: Skin aquaporins: function in hydration, wound healing, and skin epidermis homeostasis. Handb Exp Pharmacol 2009;190:205-217.

12 Ma L, Huang YG, Deng YC, Tian JY, Rao ZR, Che HL, Zhang HF, Zhao G: Topiramate reduced sweat secretion and aquaporin-5 expression in sweat glands of mice. Life Sci 2007;80:2461-2468. 


\begin{tabular}{l|l}
\hline DOI: $10.1159 / 000346744$ & $\begin{array}{l}\text { C } 2013 \text { S. Karger AG, Basel } \\
\text { www.karger.com/cde }\end{array}$ \\
\hline
\end{tabular}

Gündüz et al.: Aquagenic Palmar Wrinkling Induced by Combined Use of Salazopyrin and Indomethacin

13 Kabashima K, Shimauchi T, Kobayashi M, Fukamachi S, Kawakami C, Ogata M, Kabashima R, Mori T, Ota T, Fukushima S, Hara-Chikuma M, Tokura Y: Aberrant aquaporin 5 expression in the sweat gland in aquagenic wrinkling of the palms. J Am Acad Dermatol 2008;59(2 suppl 1):S28-S32.

-14 Jensen AM, Bae EH, Nørregaard R, Wang G, Nielsen S, Schweer H, Kim SW, Frøkiaer J: Cyclooxygenase 2 inhibition exacerbates AQP2 and pAQP2 downregulation independently of V2 receptor abundance in the postobstructed kidney. Am J Physiol Renal Physiol 2010;298:F941-F950.

15 Lauridsen TG, Vase H, Starklint J, Graffe CC, Bech JN, Nielsen S, Pedersen EB: Increased renal sodium absorption by inhibition of prostaglandin synthesis during fasting in healthy man. A possible role of the epithelial sodium channels. BMC Nephrol 2010;11:28. 


\section{Case Reports in Dermatology}

\begin{tabular}{l|l}
\hline Case Rep Dermatol 2013;5:21-26 \\
\hline DOI: $\underline{10.1159 / 000346744}$ & $\begin{array}{l}\text { ○ } 2013 \text { S. Karger AG, Basel } \\
\text { www.karger.com/cde }\end{array}$ \\
\hline
\end{tabular}

Gündüz et al:: Aquagenic Palmar Wrinkling Induced by Combined Use of Salazopyrin and Indomethacin
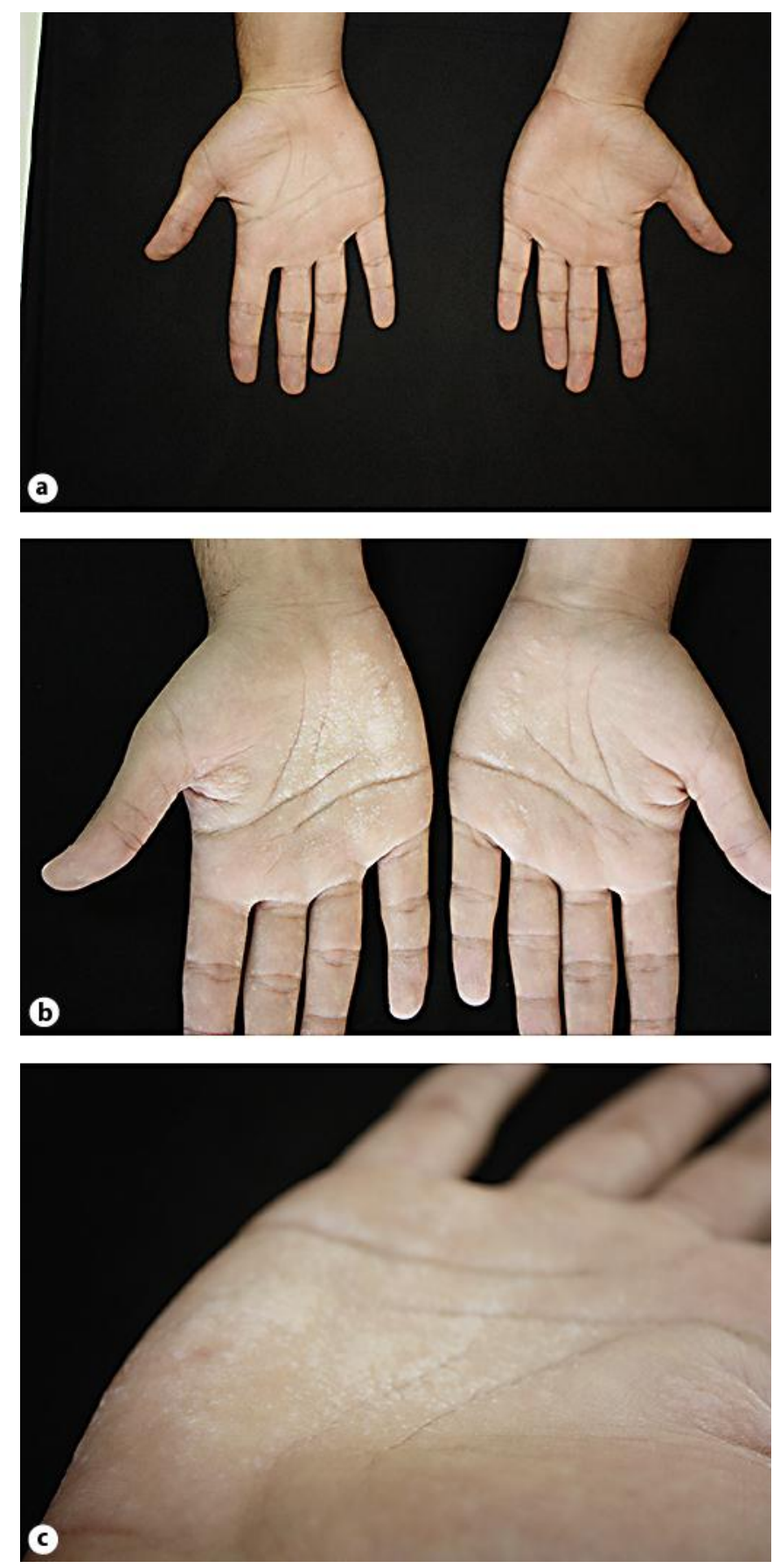

Fig. 1. Comparison of pre- and postimmersion. a Palmar side of the hands, before washing under tap water. $\mathbf{b}$ White, flat papules, more prominent on the right palm after water immersion. c Close-up view of palmar papules. 

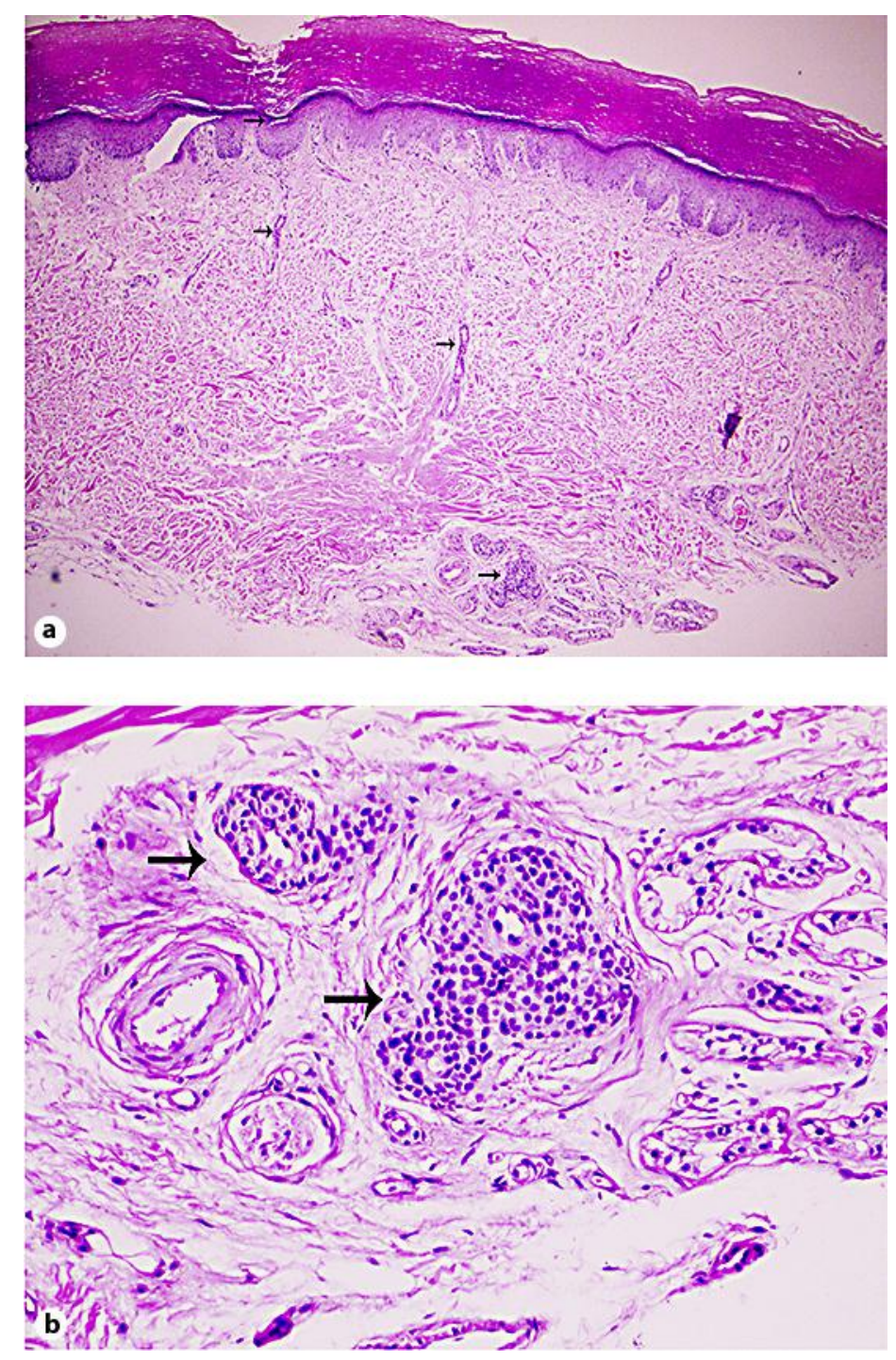

Fig. 2. a Orthokeratosis and eccrine ducts with irregular lumina and some dilatation (arrows) (hematoxylin and eosin, original magnification $\times 100$ ). b Hyperplasia of eccrine glandular epithelia (arrows) (hematoxylin and eosin, original magnification $\times 200$ ). 